\title{
Diagnostic value of CT-colonography as compared to colonoscopy in an asymptomatic screening population: a meta-analysis
}

\author{
Margriet C. de Haan • Rogier E. van Gelder • \\ Anno Graser • Shandra Bipat • Jaap Stoker
}

Received: 14 November 2010 /Revised: 1 February 2011 /Accepted: 3 February 2011 /Published online: 1 April 2011

(C) The Author(s) 2011. This article is published with open access at Springerlink.com

\begin{abstract}
Objectives Previous meta-analyses on CT-colonography included both average and high risk individuals, which may overestimate the diagnostic value in screening. A meta-analysis was performed to obtain the value of CTcolonography for screening.

Methods A search was performed using PubMed, Embase and Cochrane. Article selection and critical appraisal was done by two reviewers. Inclusion criteria: prospective, randomized trials or cohort studies comparing CTcolonography with colonoscopy ( $\geq 50$ participants), $\geq 95 \%$ average risk participants $\geq 50$ years. Study characteristics and $2 \times 2$ contingency Tables were recorded. Sensitivity and specificity estimates were calculated per patient and per polyp ( $\geq 6 \mathrm{~mm}, \geq 10 \mathrm{~mm}$ ), using univariate and bivariate analyses.

Results Five of 1,021 studies identified were included, including 4,086 participants ( $<1 \%$ high risk). $\mathrm{I}^{2}$-values showed substantial heterogeneity, especially for 6-9 $\mathrm{mm}$
\end{abstract}

\footnotetext{
M. C. de Haan · R. E. van Gelder · S. Bipat · J. Stoker Department of Radiology, Academic Medical Center, University of Amsterdam,

Amsterdam, The Netherlands

A. Graser

Department of Clinical Radiology, Klinikum Grosshadern, University of Munich,

Munich, Germany

M. C. de Haan $(\bowtie)$

Department of Radiology, G1-223.1, Academic Medical Center, Amsterdam,

Meibergdreef 9,

1105 AZ, Amsterdam, The Netherlands

e-mail: m.c.dehaan@amc.uva.nl
}

polyps and adenomas: $68.1 \%$ vs. $78.6 \%$ (sensitivity per patient). Estimated sensitivities for patients with polyps or adenomas $\geq 6 \mathrm{~mm}$ were $75.9 \%$ and $82.9 \%$, corresponding specificities $94.6 \%$ and $91.4 \%$. Estimated sensitivities for patients with polyps or adenomas $\geq 10 \mathrm{~mm}$ were $83.3 \%$ and $87.9 \%$, corresponding specificities $98.7 \%$ and $97.6 \%$. Estimated sensitivities per polyp for advanced adenomas $\geq 6 \mathrm{~mm}$ and $\geq 10 \mathrm{~mm}$ were $83.9 \%$ and $83.8 \%$.

Conclusion Compared to colonoscopy, CT-colonography has a high sensitivity for adenomas $\geq 10 \mathrm{~mm}$. For (advanced) adenomas $\geq 6 \mathrm{~mm}$ sensitivity is somewhat lower.

Keywords Colorectal cancer · Screening ·

CT-Colonography $\cdot$ Colonoscopy $\cdot$ Sensitivity and specificity

\section{Introduction}

Computed tomography (CT)-colonography has been studied for screening for (precursors of) colorectal cancer (CRC) and the Multisociety Task Force on Colorectal Cancer has indicated CT-colonography as an acceptable technique for CRC screening [1, 2]. However, recently the National Institute of Health has published a statement regarding CRC screening concluding that there is still lack of information regarding the use of CT-colonography as screening technique in an average risk population [3]. Also other guidelines state that there is insufficient evidence yet $[4,5]$.

Several meta-analyses have been published on the diagnostic value of CT-colonography including both average risk and high risk individuals, but no meta-analysis has been published including average risk individuals only [610]. Individuals are considered to be at average risk if they have no symptoms, no personal history of CRC, 
adenomatous polyps or inflammatory bowel disease and no family history of advanced neoplasia [11]. By including studies containing high risk populations, the diagnostic value of CT-colonography in an average risk population might be overestimated. It is known that the estimated diagnostic value of a technique depends on factors such as disease prevalence and spectrum.

Therefore, the aim of this meta-analysis was to estimate the diagnostic value of CT-colonography to detect (advanced) adenomas and CRC in an average risk population aged 5075 years.

\section{Materials and methods}

\section{Literature search}

Articles were obtained from the electronic databases PubMed, Embase and Cochrane, without restrictions with respect to the publication date and language. Lists of synonyms for CT-colonography were produced (Fig. 1) and combined using the Boolean operator "OR". The same was done for colonoscopy. Both search results were combined, using the Boolean operator "AND". By reading title and abstract of all retrieved articles, two observers identified possible relevant papers, based on the inclusion and exclusion criteria described below. The remaining articles were retrieved as full-text articles and independently checked by two reviewers. Disagreement regarding inclusion was resolved by consensus. Reference lists of the final selection of articles were checked manually to identify other relevant papers. If additional information of an article considered for inclusion was needed due to incomplete data or description of the methods, the corresponding authors were contacted.

\section{Inclusion and exclusion criteria}

Inclusion criteria were prospective, randomized trials or cohort studies, in humans $\geq 50$ years, in which at least 50 predominantly asymptomatic average risk subjects $(\geq 95 \%)$ underwent CT-colonography and completed colonoscopy for verification within 3 months. In addition, eligible studies needed to report the detection of colorectal polyps (adenomatous and non-adenomatous), advanced neoplasia and CRC and should include true-positive (TP), falsepositive (FP), true-negative (TN) and false-negative (FN) values. Studies that included predominantly high risk subjects (symptomatic, history of hereditary CRC, personal history of polyps, CRC or IBD) were excluded, as well as studies that performed CT-colonography as a consequence of incomplete colonoscopy or studies that only performed colonoscopy after positive findings on CT-colonography.
Quality assessment

Systematic assessment of quality and documentation of relevant data of the selected articles was performed independently by two reviewers, using a standardized form. To grade the study quality, the Quality Assessment of Diagnostic Accuracy Studies (QUADAS) tool was used with special focus on the characteristics of the included study population, index test and reference test [12]. We assessed whether the inclusion and exclusion criteria were described clearly and would result in a representative screening cohort. In addition, the presence of a disease progression bias and a verification bias was determined: did all participants receive their reference test $<3$ months? Furthermore, we assessed whether the index test did not form part of the reference standard, whether all subjects received the same reference test, if the test results of both test were interpreted without knowledge of the other test results and whether withdrawals or uninterpretable test results were reported. Results are presented in Appendix 1.

\section{Study population}

The following patient characteristics were documented: number of asymptomatic and symptomatic subjects, sex ratio, mean or median age with age range and CTcolonography indication.

\section{Imaging features}

The following characteristics were documented regarding the imaging features of CT-colonography: bowel preparation, dietary restrictions, tagging and bowel distention, use of spasmolytical drugs and type of CT-system and CTparameters, the positioning of the patient and the use of intravenous contrast medium during CT-colonography. For colonoscopy, the type of bowel preparation and dietary restrictions were documented.

Imaging and diagnostic criteria

The following characteristics were documented regarding image analysis of both CT-colonography and colonoscopy: number of diagnostic examinations, number and experience of CT-colonography readers and endoscopists, reading strategy on CT-colonography, use of segmental unblinding or second look colonoscopy, determination of size on CT-colonography and during colonoscopy and histopathological confirmation.

\section{Data extraction}

For the analysis per patient, $2 \times 2$ contingency tables were constructed to be able to calculate the sensitivity and 
Fig. 1 Flowchart of search strategy, search date: 21 st of July, 2010

\section{Produce list of synonyms}

(Colonography (includes: CT colonography, CT colonography screening, virtual colonography) OR colography OR CTC OR computerized tomographic colonoscopy OR virtual colonoscopy OR virtual endoscopy OR ct colonoscopy OR ct pneumocolon) AND

(Colonoscopy (includes:optical colonoscopy) OR coloscopy OR OC)

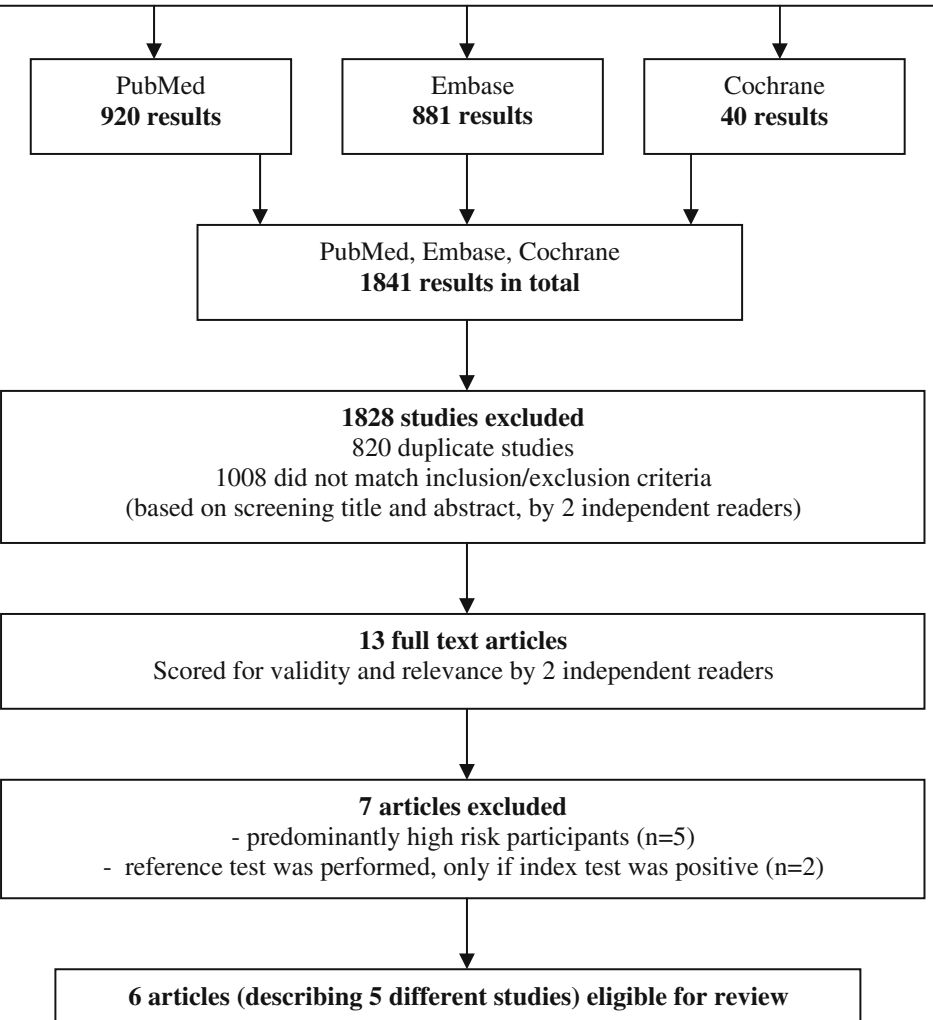

specificity values for the following type of lesions: all polyps, adenomatous polyps, advanced adenomas (defined as an adenoma with $>25 \%$ villous features, size $\geq 10 \mathrm{~mm}$ and/or high grade dysplasia [13]), advanced neoplasia and CRC. For each type of lesion, except for CRC, data were collected using the following thresholds: $6-9 \mathrm{~mm}, \geq 6 \mathrm{~mm}$ and $\geq 10 \mathrm{~mm}$, based on the associated potential CRC risk [14-16].

For the analysis per polyp, we extracted TP and FN findings to calculate the sensitivity of all polyps, (advanced) adenomas and advanced neoplasia for the same thresholds.

If needed, a request for additional data was send to the corresponding author. If possible, the following matching algorithm was used: the lesion should be at least $<50 \%$ margin of error in size and should be found in the same or adjacent segment.

\section{Statistical analysis}

Heterogeneity of sensitivity or specificity was assessed using $\mathrm{I}^{2}$ statistics [17]. If $\mathrm{I}^{2}$ values were $>25 \%$, we considered these data significantly heterogeneous, and random-effects analyses were performed. In case of $\mathrm{I}^{2-}$ values $<25 \%$, fixed-effects approaches were used.

For the per-patient analyses, we used bivariate models [18] to obtain summary estimates of sensitivity and specificity with $95 \%$ confidence intervals. For the perpolyp analyses, we used univariate models to obtain summary estimates of sensitivity with $95 \%$ confidence intervals. All analyses were performed using SAS software (SAS 9.2 procNlmixed, SAS Institute, Cary, NC, USA).

Publication bias was examined by constructing funnel plots.

Per patient The $\mathrm{x}$-axis consisted of the natural logarithm of the diagnostic odds ratio $(=(\mathrm{TP} \times \mathrm{TN}) /(\mathrm{FN} \times \mathrm{FP}))$. On the $y$-axis, we plotted the number of patients.

Per-lesion The $\mathrm{x}$-axis consisted of the sensitivity and on the $y$-axis, we plotted the number of patients.

Egger's regression tests were used to examine the asymmetry of the funnel plots. A significant regression coefficient $(P<0.05)$ indicates an association between sample size and the diagnostic values. 


\section{Results}

The initial search yielded 1,841 articles (Fig. 1). By excluding doubles, 1,021 articles remained. After screening on title and abstract, 1,008 articles were excluded. The most frequent reasons for exclusion were study design, study population (i.e. high risk) or non-related to CT-colonography or screening for polyps and CRC (i.e. IBD, MR-colonography). After assessment of 13 full text publications, seven articles were excluded, because they included only $(n=2)[19,20]$ or predominantly $(n=4)$ high risk participants $(16.7 \%, 37.0 \%, 76.6 \%$ and $80.4 \%$, respectively)[21-24] or because colonoscopy was only offered to a small selection of the participants $(n=1)$ [25]. Finally, six articles were included in this systematic review describing the results found in five prospective cohort studies [26-31]. Screening of title and abstract of references and related articles did not result in additional relevant articles.

\section{Patient characteristics}

Patient characteristics are outlined in Table 1 . We included five studies with in total 4,086 patients (54\% male). Four studies [26-28, 30, 31] did have a study population of over 200 average risk subjects, the largest population comprised 2,249 average risk subjects [27]. The smallest study had a population of 68 participants at average risk [29]. All studies provided a clear description of patient characteristics and the inclusion and exclusion criteria. Three studies included high risk subjects: $2.6 \%$ [30, 31], 5.2\% [28] and $11.3 \%$ [27], respectively. The corresponding authors of these papers were contacted to obtain data concerning average risk patients only. This succeeded in two out of three studies, resulting in a total of four datasets containing data of average risk subjects only [26-29] and one study including $2.6 \%$ high risk participants [30, 31]. Resulting in a total of 4,086 participants, of which 37 were at high risk $(0.9 \%)$. The mean age varied between 55 and 60.5 years, the minimal age was 50 in four studies [26-29].

\section{Bowel preparation and CT-colonography procedure}

Bowel preparation and CT-colonography procedure are outlined in Appendix 2.

Three studies used an extensive bowel preparation predominantly based on 4 liters polyethylene glycol [2628] combined with a clear liquid diet [26], a low-residue diet [28] or dietary restrictions depending on the institutional standard of the clinical centres where the examinations were done [27]. The remaining two studies both used a more limited preparation based on sodium phosphate [2931]. One study combined this with a clear liquid diet [30, $31]$, the dietary restrictions of the other study were not specified [29].
Three studies used oral tagging [26, 27, 30, 31], one study did use intravenous contrast medium [28]. Of one study it was not specified whether the participants received tagging [29]. Bowel preparation was the same for colonoscopy, as both colonoscopy and CT-colonography were performed on the same day in all studies.

Bowel distension methods varied between the studies. Two studies used (primarily) automated $\mathrm{CO}_{2}$ insufflation, combined with butylscopolamine bromide (Buscopan, Boehringer, Ingelheim, Germany) [26] or glucagonhydrochloride (GlucaGen, Novo Nordisk A'S, Bagsvaerd, Denmark) as spasmolytical drug [27]. Three studies used manual room air [28-31]. In one study no spasmolytical drug was administered [28], it was not specified whether spasmolytical drugs were used in the remaining two studies [29-31]. Two studies used at least 4 slice CT equipment [29-31], two studies used at least 16 slice CT [27, 28] and one study used 64 slice CT [26].

\section{Study characteristics}

Study characteristics are outlined in Appendix 3. All participants received CT-colonography and colonoscopy on the same day. Different reference standards were used. One study used the colonoscopy results without knowledge of the CT-colonography findings [29], two studies used the colonoscopy result after segmental unblinding as reference [26, 30, 31], one study used colonoscopy (followed by a second look colonoscopy if lesions $\geq 10 \mathrm{~mm}$ reported on CTC were missed on the initial colonoscopy) combined with histopathology as reference [27] and another study used the histopathology results of the polyps that were removed during colonoscopy after segmental unblinding [28]. It is unclear whether there were any withdrawals in the selected studies. Uninterpretable results of CT-colonography or colonoscopy (outlined in Table 1) were reported and excluded from the analyses in two studies [26, 30, 31].

Image analysis

The characteristics of the readers and the reading strategy are outlined in Appendix 3. The minimal experience of the CT-colonography readers was specified in four out of five studies, and varied between 25 and 100 examinations [26$28,30,31]$. In one study the only reader had 5 years of reading experience [29]. Two studies used 2D read as primary reading strategy [28, 29], two studies used 3D read $[26,30,31]$ and one study used both reading strategies at random [27]. None of the included studies specified whether $\mathrm{CAD}$ was used. The experience of the endoscopists and use of different scopes of the included studies was not specified in most studies [27, 29-31]. One study had been done by gastroenterologists with a minimum experience of 1,000 


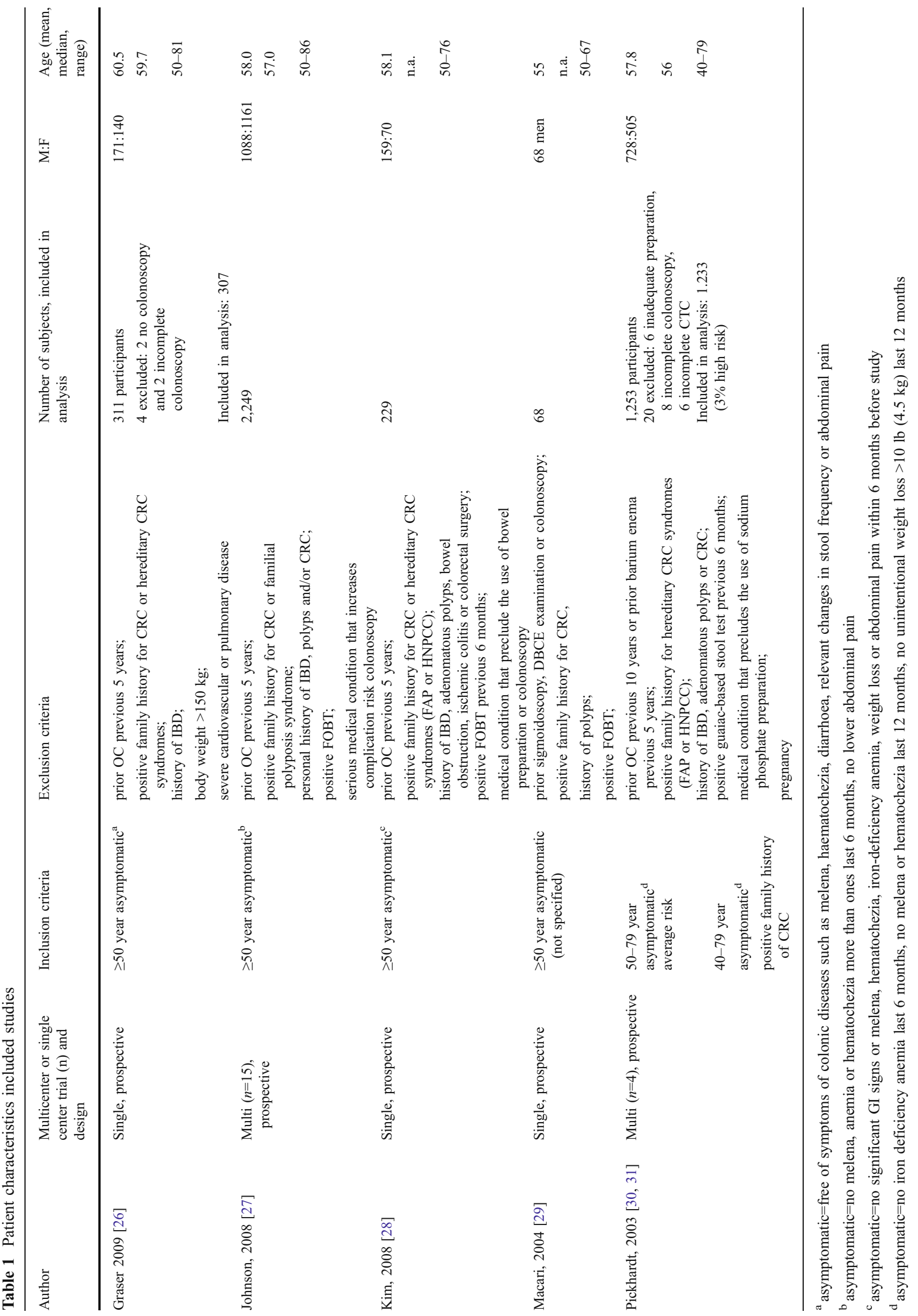


colonoscopies [26], while the gastroenterologists in another study had a prior experience of 3,000 colonoscopies [28].

Size measurement of the polyp was done by the use of an open biopsy forceps [26, 28, 29], by a calibrated linear probe $[30,31]$ or determined by the pathologist [27]. In all studies histopathology confirmation was available.

\section{Data extraction}

Four studies used a matching algorithm almost the same as the one described in the methods [26, 28-31]. These studies considered a CT-colonography finding to correspond with a colonoscopy lesion, if it was found in the same or adjacent segment. In addition it should be at least $<50 \%$ margin of error in size [28], in the same or adjacent size category [26, $30,31]$ or should have a size difference of $<4 \mathrm{~mm}$ [29] to be considered as a true positive. The fifth study [27] used a different matching algorithm: one or more lesions should be in the same size category, irrespective of location. Of this study new data were requested and received, using the matching algorithm as specified in the methods section.

Per patient data for each of the different size categories regarding all polyps and adenomas respectively, could be obtained in three respectively four of the five studies (Table 2). Per polyp data for each of the different size categories regarding all polyps could be obtained in all studies while per polyp data for adenomas could be obtained in four studies and per polyp data of advanced adenomas and CRC in three of the five studies (Table 3).

Corresponding $\mathrm{I}^{2}$ values for heterogeneity are reported in Tables 2 and 3. The results of individual studies are shown in forest plots (Figs. 2 and 3).

Table 2 Results regarding all polyps, (advanced) adenomatous polyps, colorectal cancer, advanced neoplasia: per patient

\begin{tabular}{|c|c|c|c|c|c|c|c|c|c|c|c|c|c|}
\hline & & \multicolumn{12}{|c|}{ All polyps $(n=2,853)$} \\
\hline & & \multicolumn{4}{|c|}{$6-9 \mathrm{~mm}$} & \multicolumn{4}{|c|}{$\geq 6 \mathrm{~mm}$} & \multicolumn{4}{|c|}{$\geq 10 \mathrm{~mm}$} \\
\hline & & $\mathrm{TP}$ & FP & $\mathrm{FN}$ & $\mathrm{TN}$ & $\mathrm{TP}$ & FP & FN & $\mathrm{TN}$ & $\mathrm{TP}$ & $\mathrm{FP}$ & FN & $\mathrm{TN}$ \\
\hline Graser [26] & $N=307$ & 25 & 6 & 4 & 272 & 50 & 10 & 6 & 241 & 25 & 4 & 2 & 276 \\
\hline Johnson [27] & $N=2,249$ & 78 & 58 & 51 & 2,062 & 156 & 75 & 70 & 1,948 & 78 & 17 & 19 & 2,135 \\
\hline Kim [28] & $N=229$ & 23 & 14 & 15 & 177 & 36 & 20 & 17 & 156 & 13 & 6 & 2 & 208 \\
\hline Macari [29] & $N=68$ & n.a. & n.a. & n.a. & n.a. & n.a. & n.a. & n.a. & n.a. & 3 & 1 & 0 & 64 \\
\hline Estimated sensitivity & & \multicolumn{4}{|c|}{$68.1(52.9-80.2)$} & \multicolumn{4}{|c|}{$75.9(62.3-85.8)$} & \multicolumn{4}{|c|}{$83.3(76.8-89.0)$} \\
\hline $\mathrm{I}^{2}$ heterogeneity ${ }^{\mathrm{a}}$ & & \multicolumn{4}{|c|}{$68.2 \%(29.2-85.7)$} & \multicolumn{4}{|c|}{$77.0 \%(46.0-90.2)$} & \multicolumn{4}{|c|}{$0.0 \%(0.0-82.0)$} \\
\hline Estimated specificity & & \multicolumn{4}{|c|}{$96.5(93.9-98.0)$} & \multicolumn{4}{|c|}{$94.6(90.4-97.0)$} & \multicolumn{4}{|c|}{$98.7(97.6-99.3)$} \\
\hline \multirow[t]{4}{*}{$I^{2}$ heterogeneity ${ }^{a}$} & & \multicolumn{4}{|c|}{$83.7 \%(61.7-93.1)$} & \multicolumn{4}{|c|}{$90.4 \%(78.5-95.7)$} & \multicolumn{4}{|c|}{$60.1 \%(15.2-81.2)$} \\
\hline & & \multicolumn{12}{|c|}{ Adenomatous polyps $(n=4,018)$} \\
\hline & & \multicolumn{4}{|c|}{$6-9 \mathrm{~mm}$} & \multicolumn{4}{|c|}{$\geq 6 \mathrm{~mm}$} & \multicolumn{4}{|c|}{$\geq 10 \mathrm{~mm}$} \\
\hline & & $\mathrm{TP}$ & FP & FN & $\mathrm{TN}$ & $\mathrm{TP}$ & FP & FN & $\mathrm{TN}$ & $\mathrm{TP}$ & $\mathrm{FP}$ & $\mathrm{FN}$ & $\mathrm{TN}$ \\
\hline Graser [26] & $N=307$ & 19 & 12 & 2 & 274 & 42 & 18 & 4 & 243 & 23 & 6 & 2 & 276 \\
\hline Johnson [27] & $N=2,249$ & 62 & 61 & 30 & 2,096 & 137 & 78 & 45 & 1,989 & 75 & 17 & 15 & 2,142 \\
\hline Kim [28] & $N=229$ & 22 & 6 & 11 & 190 & 31 & 18 & 12 & 168 & 9 & 12 & 1 & 207 \\
\hline Pickhardt $[30,31]$ & $N=1,233$ & 104 & 170 & 16 & 943 & 149 & 217 & 19 & 848 & 45 & 47 & 3 & 1,138 \\
\hline Estimated sensitivity & & \multicolumn{4}{|c|}{$78.6(66.1-87.3)$} & \multicolumn{4}{|c|}{$82.9(73.6-89.4)$} & \multicolumn{4}{|c|}{$87.9(82.1-92.0)$} \\
\hline $\mathrm{I}^{2}$ heterogeneity ${ }^{\mathrm{a}}$ & & \multicolumn{4}{|c|}{$79.4 \%(54.2-90.8)$} & \multicolumn{4}{|c|}{$80.2 \%(56.0-91.1)$} & \multicolumn{4}{|c|}{$14.6 \%(0.0-87.0)$} \\
\hline Estimated specificity & & \multicolumn{4}{|c|}{$95.0(89.7-97.6)$} & \multicolumn{4}{|c|}{$91.4(84.1-95.5)$} & 97.6 & $5.0-9$ & & \\
\hline $\mathrm{I}^{2}$ heterogeneity ${ }^{\mathrm{a}}$ & & 98.1 & $96.9-9$ & & & 98.4 & $(97.6-$ & $.0)$ & & 92.5 & $(85.3-$ & .2) & \\
\hline & & Adv & ed ade & nas $\geq$ & $\mathrm{nm}, \mathrm{adv}$ & ced ne & plasia $\geq$ & $\mathrm{mm} \mathrm{a}$ & $\mathrm{CRC}($ & 2,785 & & & \\
\hline & & & $\begin{array}{l}\text { aced a } \\
\text { ivity }\end{array}$ & omas & $\mathrm{mm}^{\mathrm{c}}$ & & $\begin{array}{l}\text { Colorec } \\
\text { sensitiv }\end{array}$ & al can & & & $\begin{array}{l}\text { Inced } \\
\text { tivity }\end{array}$ & oplasi & $\mathrm{mm}^{\mathrm{c}}$ \\
\hline Graser [26] & $N=307$ & & & & & & & $0 \%$ & & & & $.9 \%$ & \\
\hline Johnson [27] & $N=2,249$ & & & & & & & $0 \%$ & & & & $.0 \%$ & \\
\hline Kim [28] & $N=229$ & & & & & & & $0 \%$ & & & & $2 \%^{\mathrm{b}}$ & \\
\hline
\end{tabular}

${ }^{\mathrm{a}}$ If $\mathrm{I}^{2}$ values of sensitivity and/or specificity were larger than $25 \%$, data were considered as significantly heterogeneous

${ }^{\mathrm{b}}$ No lesions $<6 \mathrm{~mm}$ found

${ }^{\mathrm{c}}$ Not possible to calculate estimated sensitivity and specificity due to small numbers, data regarding TP, FP, FN and TN values not available 
Table 3 Results regarding all polyps, (advanced) adenomatous polyps, colorectal cancer and advanced neoplasia: per polyp

\begin{tabular}{|c|c|c|c|c|c|c|c|}
\hline & & \multicolumn{6}{|c|}{ All polyps ( $n=4,086$ participants) } \\
\hline & & \multicolumn{2}{|l|}{$6-9 \mathrm{~mm}$} & \multicolumn{2}{|l|}{$\geq 6 \mathrm{~mm}$} & \multicolumn{2}{|c|}{$\geq 10 \mathrm{~mm}$} \\
\hline & & ТР & FN & $\mathrm{TP}$ & FN & TP & $\mathrm{FN}$ \\
\hline Graser [26] & $N=307$ & 49 & 7 & 84 & 9 & 35 & 2 \\
\hline Johnson [27] & $N=2,249$ & 113 & 74 & 203 & 97 & 90 & 23 \\
\hline Kim [28] & $N=229$ & 44 & 34 & 60 & 40 & 16 & 6 \\
\hline Macari [29] & $N=68$ & 9 & 8 & 12 & 8 & 3 & 0 \\
\hline Pickhardt $[30,31]$ & $N=1,233$ & 209 & 54 & 278 & 66 & 69 & 12 \\
\hline \multicolumn{2}{|l|}{ Estimated sensitivity } & \multicolumn{2}{|c|}{$69.7(56.2-80.6)$} & \multicolumn{2}{|c|}{$74.3(61.6-83.8)$} & \multicolumn{2}{|c|}{$83.7(76.6-89.0)$} \\
\hline \multicolumn{2}{|l|}{$I^{2}$ heterogeneity ${ }^{\mathrm{a}}$} & $88.6 \%(7$ & & $89.3 \%$ & & $33.3 \%$ & \\
\hline & & \multicolumn{6}{|c|}{ Adenomatous polyps ( $n=4,018$ participants) } \\
\hline & & \multicolumn{2}{|l|}{$6-9 \mathrm{~mm}$} & \multicolumn{2}{|l|}{$\geq 6 \mathrm{~mm}$} & \multicolumn{2}{|c|}{$\geq 10 \mathrm{~mm}$} \\
\hline & & $\mathrm{TP}$ & FN & ТP & FN & ТP & $\mathrm{FN}$ \\
\hline Graser [26] & $N=307$ & 37 & 4 & 67 & 6 & 30 & 2 \\
\hline Johnson [27] & $N=2,249$ & 81 & 49 & 167 & 68 & 86 & 19 \\
\hline $\operatorname{Kim}[28]$ & $N=229$ & 31 & 21 & 44 & 25 & 13 & 4 \\
\hline Pickhardt $[30,31]$ & $N=1,233$ & 133 & 26 & 180 & 30 & 47 & 4 \\
\hline Estimated sensitivity & & $75.7(60$ & & $80.0(6$ & & 85.9 & \\
\hline \multirow[t]{4}{*}{$\mathrm{I}^{2}$ heterogeneity ${ }^{\mathrm{a}}$} & & $88.5 \%(7$ & & $89.2(7$ & & $44.9 \%$ & \\
\hline & & \multicolumn{6}{|c|}{ Advanced adenomas ( $n=2,785$ participants $)$} \\
\hline & & \multicolumn{2}{|c|}{$6-9 \mathrm{~mm}$} & \multicolumn{2}{|c|}{$\geq 6 \mathrm{~mm}$} & \multicolumn{2}{|c|}{$\geq 10 \mathrm{~mm}$} \\
\hline & & $\mathrm{TP}$ & FN & ТP & FN & TP & $\mathrm{FN}$ \\
\hline Graser [26] & $N=307$ & 6 & 0 & 36 & 2 & 30 & 2 \\
\hline Johnson [27] & $N=2,249$ & 0 & 0 & 86 & 19 & 86 & 19 \\
\hline Kim $[28]$ & $N=229$ & 6 & 2 & 19 & 6 & 13 & 4 \\
\hline Estimated sensitivity & & n.a. & & $83.9(7$ & & 83.8 & \\
\hline \multirow[t]{4}{*}{$\mathrm{I}^{2}$ heterogeneity ${ }^{\mathrm{a}}$} & & n.a. & & $51.8(1$ & & $32.3 \%$ & \\
\hline & & \multicolumn{6}{|c|}{ Colorectal cancer ( $n=2,785$ participants) } \\
\hline & & $6-9 \mathrm{~mm}$ & & $\geq 6 \mathrm{~mm}$ & & $\geq 10 \mathrm{n}$ & \\
\hline & & TP & $\mathrm{FN}$ & TP & $\mathrm{FN}$ & TP & $\mathrm{FN}$ \\
\hline Graser [26] & $N=307$ & 0 & 0 & 1 & 0 & 1 & 0 \\
\hline Johnson [27] & $N=2,249$ & 0 & 0 & 4 & 0 & 4 & 0 \\
\hline $\operatorname{Kim}[28]$ & $N=229$ & 0 & 0 & 1 & 0 & 1 & 0 \\
\hline \multicolumn{8}{|c|}{ Not possible to calculate estimated sensitivity due to small numbers } \\
\hline & & \multicolumn{6}{|c|}{ Advanced neoplasia ( $n=2,785$ participants) } \\
\hline & & \multicolumn{2}{|l|}{$6-9 \mathrm{~mm}$} & \multicolumn{2}{|l|}{$\geq 6 \mathrm{~mm}$} & \multicolumn{2}{|c|}{$\geq 10 \mathrm{~mm}$} \\
\hline & & ТP & FN & $\mathrm{TP}$ & FN & $\mathrm{TP}$ & $\mathrm{FN}$ \\
\hline Graser [26] & $N=307$ & 6 & 0 & 37 & 2 & 31 & 2 \\
\hline Johnson [27] & $N=2,249$ & 0 & 0 & 90 & 19 & 90 & 19 \\
\hline Kim [28] & $N=229$ & 6 & 2 & 20 & 6 & 14 & 4 \\
\hline
\end{tabular}

${ }^{\mathrm{a}}$ If $\mathrm{I}^{2}$ values of sensitivity and/or specificity were larger than $25 \%$, data were considered as significantly heterogeneous

Data analysis per patient

All polyps Estimated sensitivities for polyps $\geq 6 \mathrm{~mm}$ and $\geq$ $10 \mathrm{~mm}$ (regardless of histology) were $75.9 \%$ (95\%CI $62.3-$ $85.8)$ and $83.3 \%$ (95\%CI 76.8-89.0), while corresponding specificities were 94.6\% (95\%CI 90.4-97.0) and 98.7\% (95\%CI 97.6-99.3).

Adenomas Estimated sensitivities for adenomas $\geq 6 \mathrm{~mm}$ and $\geq 10 \mathrm{~mm}$ were $82.9 \%(95 \% \mathrm{CI} 73.6-89.4)$ and 
Fig. 2 Forest plot of per patient sensitivity and specificity, including sensitivity and specificity estimates, for all polyps. Summary statistics: estimated sensitivities for polyps $\geq 6 \mathrm{~mm}$ and $\geq 10 \mathrm{~mm}$ were $75.9 \%(95 \%$ CI $62.3-85.8)$ and $83.3 \%(95 \%$ CI 76.8-89.0), corresponding estimated specificities $94.6 \%$ (90.4-97.0) and $98.7 \%$ (97.6-99.3)

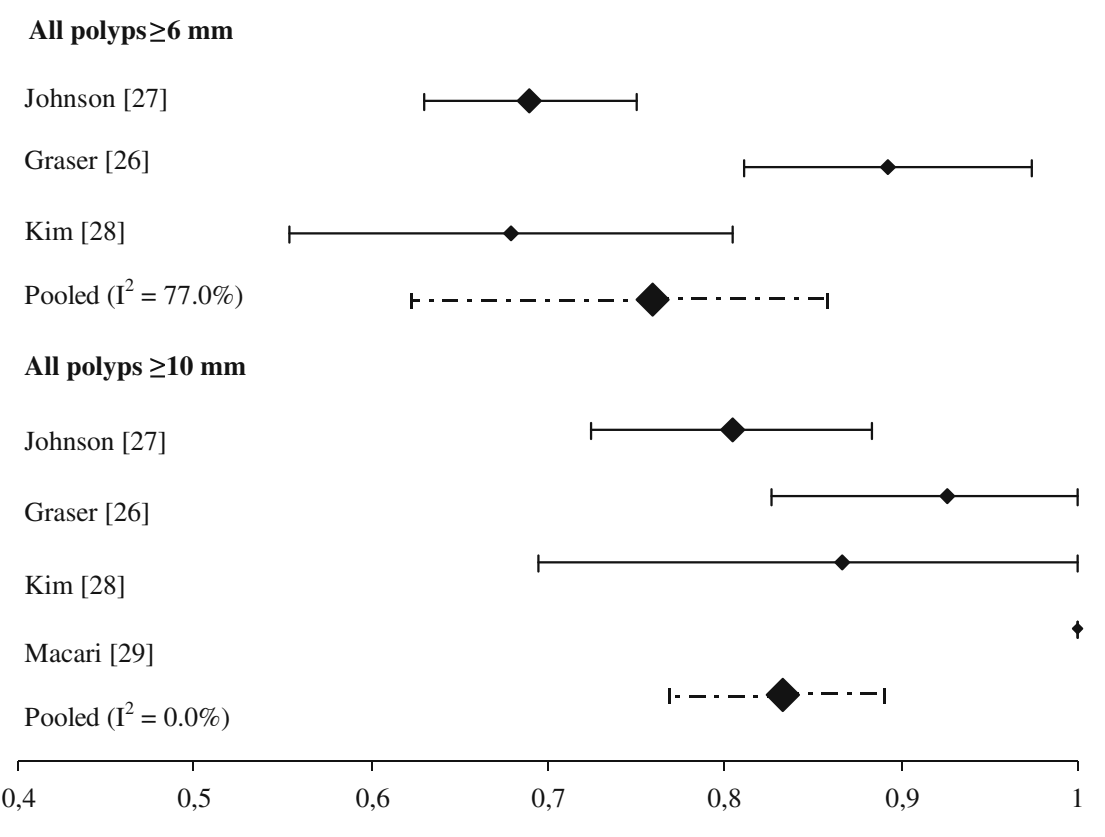

Sensitivity of CT-colonography for the detection of polyps, per patient (including 95\% CI)

All polyps $\geq 6 \mathrm{~mm}$

Johnson [27]

Graser [26]

Kim [28]

Pooled $\left(\mathrm{I}^{2}=90.4 \%\right)$

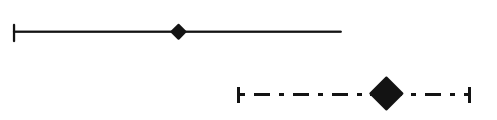

All polyps $\geq 10 \mathrm{~mm}$

Johnson [27]

Graser [26]

Kim [28]

Macari [29]

Pooled $\left(\mathrm{I}^{2}=60.1 \%\right)$

\begin{tabular}{lllllll}
\hline 0,7 & 0,75 & 0,8 & 0,85 & 0,9 & 0,95 & 1
\end{tabular}

Specificity of CT-colonography for the detection of polyps, per patient (including $95 \% \mathrm{CI}$ )
$87.9 \%$ (95\%CI 82.1-92.0), while corresponding specificities were $91.4 \%$ (95\%CI $84.1-95.5)$ and $97.6 \%$ (95\%CI 95.0-98.9).Estimated sensitivities of all polyps and adenomatous polyps of 6-9 $\mathrm{mm}$ are available in Table 2 .

Advanced adenomas, CRC and advanced neoplasia Estimated results for the detection of advanced adenomas, advanced neoplasia and $\mathrm{CRC}$ were not calculated, as a consequence of the small number of participants with these findings (Table 2).

Data analysis per polyp

All polyps Estimated sensitivities for polyps $\geq 6 \mathrm{~mm}$ and $\geq 10 \mathrm{~mm}$ (regardless of histology), were $74.3 \%$ (95\%CI 61.6-83.3) and 83.7\% (95\%CI 76.6-89.0). 
Fig. 3 Forest plot of per patient sensitivity and specificity, including sensitivity and speci-

ficity estimates, for adenomas

Summary statistics: estimated sensitivities for adenomas

$\geq 6 \mathrm{~mm}$ and $\geq 10 \mathrm{~mm}$ were 82.9

(73.6-89.4) and $87.9(82.1-$

92.0), corresponding estimated specificities $91.4(84.1-95.5)$ and $97.6(95.0-98.9)$
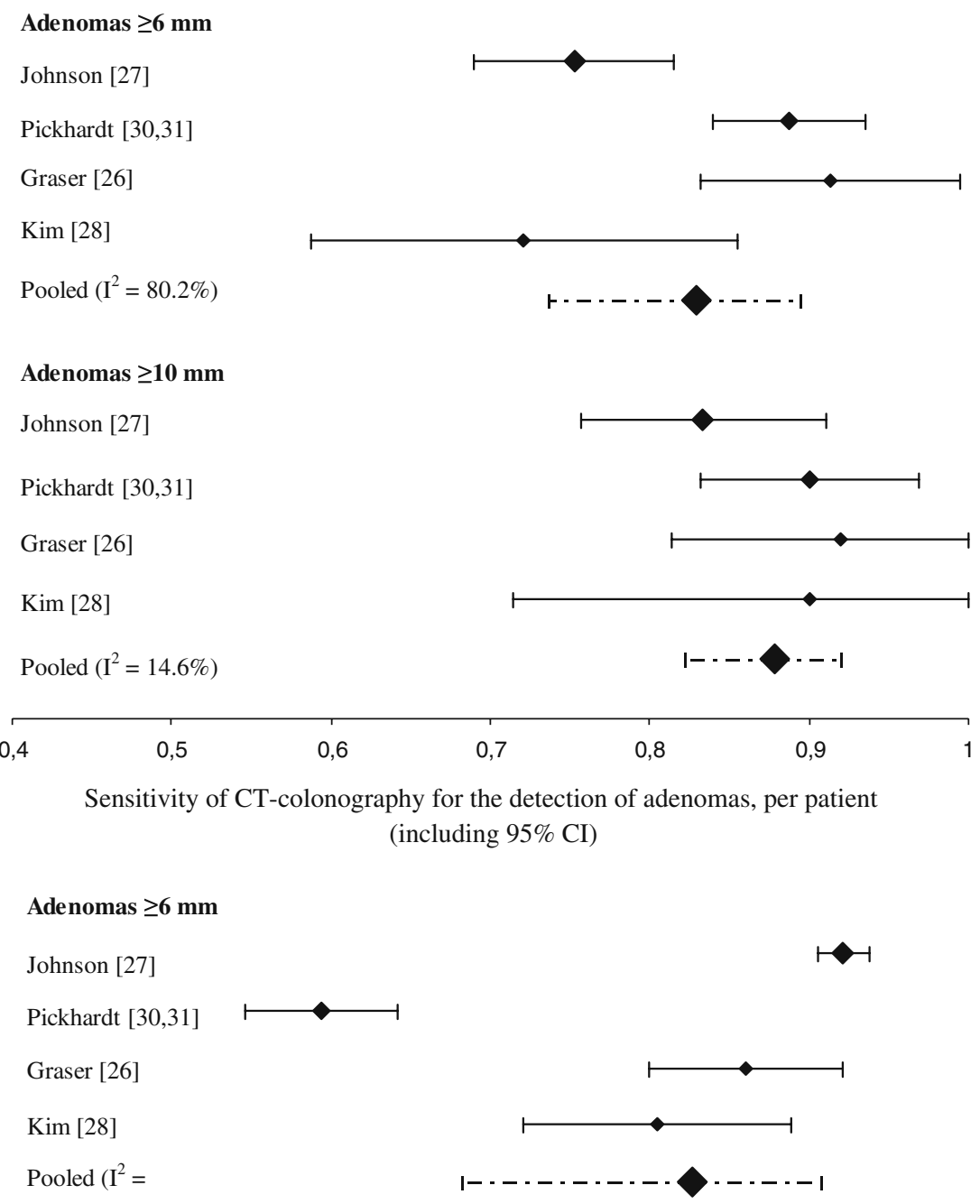

Adenomas $\geq 10 \mathrm{~mm}$

Johnson [27]

Pickhardt $[30,31]$

Graser [26]

$\operatorname{Kim}[28]$

Pooled $\left(\mathrm{I}^{2}=\right.$

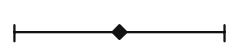

\begin{tabular}{llllll}
\hline 0,7 & 0,75 & 0,85 & 0,9 & 0,95 & 1
\end{tabular}

Specificity of CT-colonography for the detection of adenomas, per patient (including 95\% CI)

Adenomas Estimated sensitivities for adenomas $\geq 6 \mathrm{~mm}$ and $\geq 10 \mathrm{~mm}$ were $80.0 \%(95 \% \mathrm{CI} 66.9-88.7)$ and $85.9 \%$ (95\%CI 80.4-90.0).

Advanced adenomas Estimated sensitivities for advanced adenomas $\geq 6 \mathrm{~mm}$ and $\geq 10 \mathrm{~mm}$ were $83.9 \%$ (95\%CI 77.6-88.7) and $83.3 \%(95 \% \mathrm{CI} 77.1-88.8)$. Estimated sensitivities for polyps and (advanced) adenomas of 6$9 \mathrm{~mm}$, are presented in Table 3 .

Advanced neoplasia and CRC Estimated sensitivities for advanced neoplasia and CRC by CT-colonography were not calculated, as a consequence of the small number of CRCs $(n=6)$ that were detected in the 
included studies. In all studies, no CRCs were missed (Table 3).

\section{Publication bias}

The data points in the funnel plots are symmetrically distributed in a funnel shape suggesting the absence of publication bias (Appendix 4a-5b). In addition, the Egger's regression tests showed no associations between sample size and diagnostic values (data not shown).

\section{Discussion}

This systematic review demonstrates an estimated per patient sensitivity and specificity of CT-colonography for the detection of adenomas $\geq 6 \mathrm{~mm}$ of $82.9 \%$ (95\% CI $74-$ $89 \%$ ) and $91.4 \%$ (95\%CI $84-96 \%)$ in asymptomatic screening participants. The estimated per patient sensitivity and specificity for adenomas $\geq 10 \mathrm{~mm}$, were $87.9 \%(95 \% \mathrm{CI}$ $82-92 \%$ ) and $97.6 \%$ (95\%CI 95-99\%). The estimated per patient sensitivities for all colorectal polyps were slightly lower. All six CRCs were detected by CT-colonography.

As we obtained additional data of the studies in which high risk participants were excluded [27, 28], the study results might not be identical to previously published data. In addition, the results of Johnson et al. [27] are different then published before, as we used a different matching algorithm then the one that was used in their study, resulting in lower sensitivities and higher specificities.

There are a few explanations available for the substantial variability between studies in sensitivity and specificity. The largest study [27] ( $n=2,249$ participants), did not report lesions $<5 \mathrm{~mm}$ found on CT-colonography (while a colonoscopy lesion of $6 \mathrm{~mm}$ could match a CTC lesion of $3 \mathrm{~mm}$ ) and performed no second look colonoscopy for colonoscopy negative CTC lesions $<10 \mathrm{~mm}$. Obviously, both factors will probably result in a lower sensitivity for medium sized adenomas and a less prominent difference in the detection of adenomas $\geq 10 \mathrm{~mm}$ compared to the studies of Graser [26] and Pickhardt [30, 31]. The second explanation could be the use of primary $2 \mathrm{D}$ or primary 3D read: those studies with the highest sensitivities for the detection of adenomas used primary $3 \mathrm{D}$ read [26, 30, 31]; the other studies used primary $2 \mathrm{D}$ read $[28,29]$ or both methods randomly [27]. However, there is conflicting evidence regarding the possible difference of sensitivity when using primary $2 \mathrm{D}$ or $3 \mathrm{D}$ read $[32,33]$.

To our knowledge this is the first meta-analysis in which the diagnostic value of CT-colonography is compared to colonoscopy for the detection of (adenomatous) polyps and $\mathrm{CRC}$ in an average risk population. Previously, at least five systematic reviews [6-10] were published describing the diagnostic value of CT-colonography in general (not specified for (advanced) adenomas), including both average risk and high risk populations. By comparing our results to the estimated sensitivities per patient for polyps $6-9 \mathrm{~mm}$ and $\geq 10 \mathrm{~mm}$ published previously, we found lower sensitivities, especially when looking at polyps of $6-$ $9 \mathrm{~mm}$. Estimated sensitivities per patient for polyps 6$9 \mathrm{~mm}$ published before were $59 \%, 70 \%, 84 \%$ and $86 \%$, respectively $[6-8,10]$, while we calculated an estimated sensitivity of $68.1 \%$. Estimated sensitivities per patient for polyps $\geq 10 \mathrm{~mm}$ were $76 \%, 85 \%, 88 \%$ and $93 \%$, respectively $[6-8,10]$, while we calculated an estimated sensitivity of $83.3 \%$. The fifth meta-analysis reported results using different thresholds [9].

Our study has several strengths. We aimed to use data on average risk participants only and collected data regarding all polyps, (advanced) adenomas and CRC. This provided the possibility to estimate the diagnostic value of CTcolonography for adenomas and CRC in a screening setting. In order to perform an unbiased study selection, two reviewers independently selected possible relevant articles.

Our study also has several limitations. Although we tried to include only individuals at average risk, we could not obtain these data from one study [30, 31]. Therefore, 37 individuals $(0.9 \%)$ at high risk were included. However, it is assumable that this will be daily practice in screening and it is unlikely that this small number will have a substantial impact on the results.

Secondly, participants of two studies comprised the majority of included participants, which might give the impression that this meta-analysis is actually a two study meta-analysis. However, the results of the two largest studies were heterogeneous and, moreover, were not at one end of the spectrum of the sensitivity or specificity range. Therefore it is unlikely that the larger studies skewed the results in one direction (of higher or lower values). Furthermore, sensitivity and specificity estimates were calculated using statistical analyses in which the individual studies are weighted by number of included participants [18].

Thirdly, we did not calculate the negative predictive value (NPV) because the prior probability of a negative outcome was high [34].

Fourthly, it is known that colonoscopy is not $100 \%$ sensitive for colorectal lesions and therefore no perfect reference standard [35]. Using the colonoscopy results after segmental unblinding and compared with histology, would be the best reference standard.

Fifthly, because of limited data we were not able to calculate estimated sensitivities per patient for the detection of advanced adenomas, advanced neoplasia and CRC. 
In summary, this meta-analysis of prospective studies studying the diagnostic value of CT-colonography compared to colonoscopy in an average risk population, shows that CT-colonography has a good sensitivity for (advanced) adenomas $\geq 10 \mathrm{~mm}$. For (advanced) adenomas $\geq 6 \mathrm{~mm}$ sensitivity is somewhat lower.
Acknowledgment The authors acknowledge the authors of the included studies [26, 28-31] and the American College of Radiology Imaging Network [27] for providing us with additional data.

Open Access This article is distributed under the terms of the Creative Commons Attribution Noncommercial License which permits any noncommercial use, distribution, and reproduction in any medium, provided the original author(s) and source are credited.

\section{Appendix 1}

Table 4 Quality assessment of all included studies using the QUADAS-tool

\begin{tabular}{|c|c|c|c|c|c|}
\hline & $\begin{array}{l}\text { Graser, } \\
2009[26]\end{array}$ & $\begin{array}{l}\text { Johnson, } \\
2008[27]\end{array}$ & $\begin{array}{l}\text { Kim, } \\
2008 \text { [28] }\end{array}$ & $\begin{array}{l}\text { Macari, } \\
2004[29]\end{array}$ & $\begin{array}{l}\text { Pickhardt, } \\
2003[30,31]\end{array}$ \\
\hline $\begin{array}{l}\text { Spectrum of patients representative of the patients who will receive } \\
\text { the test in practice? }\end{array}$ & Yes & Yes & Yes & Yes & Yes \\
\hline Were selection criteria clearly described? & Yes & Yes & Yes & Yes & Yes \\
\hline $\begin{array}{l}\text { Is the reference standard likely to correctly classify the target } \\
\text { condition? }\end{array}$ & Yes & Yes & Yes & Yes & Yes \\
\hline $\begin{array}{l}\text { Is the time period between reference standard and index test short } \\
\text { enough to prevent change of the target condition between the two } \\
\text { tests? }\end{array}$ & $\begin{array}{l}\text { Yes, same } \\
\text { day }\end{array}$ & $\begin{array}{l}\text { Yes, same } \\
\text { day }\end{array}$ & $\begin{array}{l}\text { Yes, same } \\
\text { day }\end{array}$ & $\begin{array}{l}\text { Yes, same } \\
\text { day }\end{array}$ & $\begin{array}{l}\text { Yes, same } \\
\text { day }\end{array}$ \\
\hline $\begin{array}{l}\text { Did all subjects receive verification using a reference standard of } \\
\text { diagnosis? }\end{array}$ & Yes & Yes & Yes & Yes & Yes \\
\hline $\begin{array}{l}\text { Did all subjects receive the same reference standard regardless of } \\
\text { the index test result? }\end{array}$ & Yes & Yes & Yes & Yes & Yes \\
\hline Was the reference standard independent of the index test? & $\mathrm{No}^{2}$ & No, partly ${ }^{3}$ & $\mathrm{No}^{2}$ & Yes & $\mathrm{No}^{2}$ \\
\hline $\begin{array}{l}\text { Execution of the index test described in sufficient detail to permit } \\
\text { replication? }\end{array}$ & Yes & Yes & Yes & Yes & Yes \\
\hline $\begin{array}{l}\text { Execution of the reference standard described in sufficient detail to } \\
\text { permit replication? }\end{array}$ & Yes & Yes & Yes & Yes & Yes \\
\hline $\begin{array}{l}\text { Were the index test results interpreted without knowledge of the } \\
\text { results of the reference standard? }\end{array}$ & Yes & Yes & Yes & Yes & Yes \\
\hline $\begin{array}{l}\text { Were the reference standard results interpreted without knowledge } \\
\text { of the results of the index test? }\end{array}$ & Yes & Yes & Yes & Yes & Yes \\
\hline $\begin{array}{l}\text { Were the same clinical data available when test results were } \\
\text { interpreted as would be available when the test is used in } \\
\text { practice? }\end{array}$ & Yes & Yes & Yes & Yes & Yes \\
\hline Were uninterpretable/intermediate test results reported? & Yes & Yes, partly ${ }^{4}$ & Unclear & Unclear & Yes \\
\hline Were withdrawals from the study explained? & Unclear $^{5}$ & Unclear $^{5}$ & Unclear $^{5}$ & Unclear $^{5}$ & Unclear $^{5}$ \\
\hline VALID & Yes & Yes & Yes & Yes & Yes \\
\hline RELEVANT & Yes & Yes & Yes & Yes & Yes \\
\hline
\end{tabular}

${ }^{1}$ Defined as $<3$ months.

${ }^{2}$ Reference standard=colonoscopy after segmental unblinding or second look colonoscopy

${ }^{3}$ Reference standard=colonoscopy followed by a second look colonoscopy if there was no match for polyps $>9$ mm on CT-colonography

${ }^{4}$ Of the 2,600 subjects recruited, 69 subjects were excluded in the analysis as a consequence of incomplete colonoscopy and/or CT-colonography results, not further specified.

${ }^{5}$ In none of the studies was explained whether there were any withdrawals from the study. 


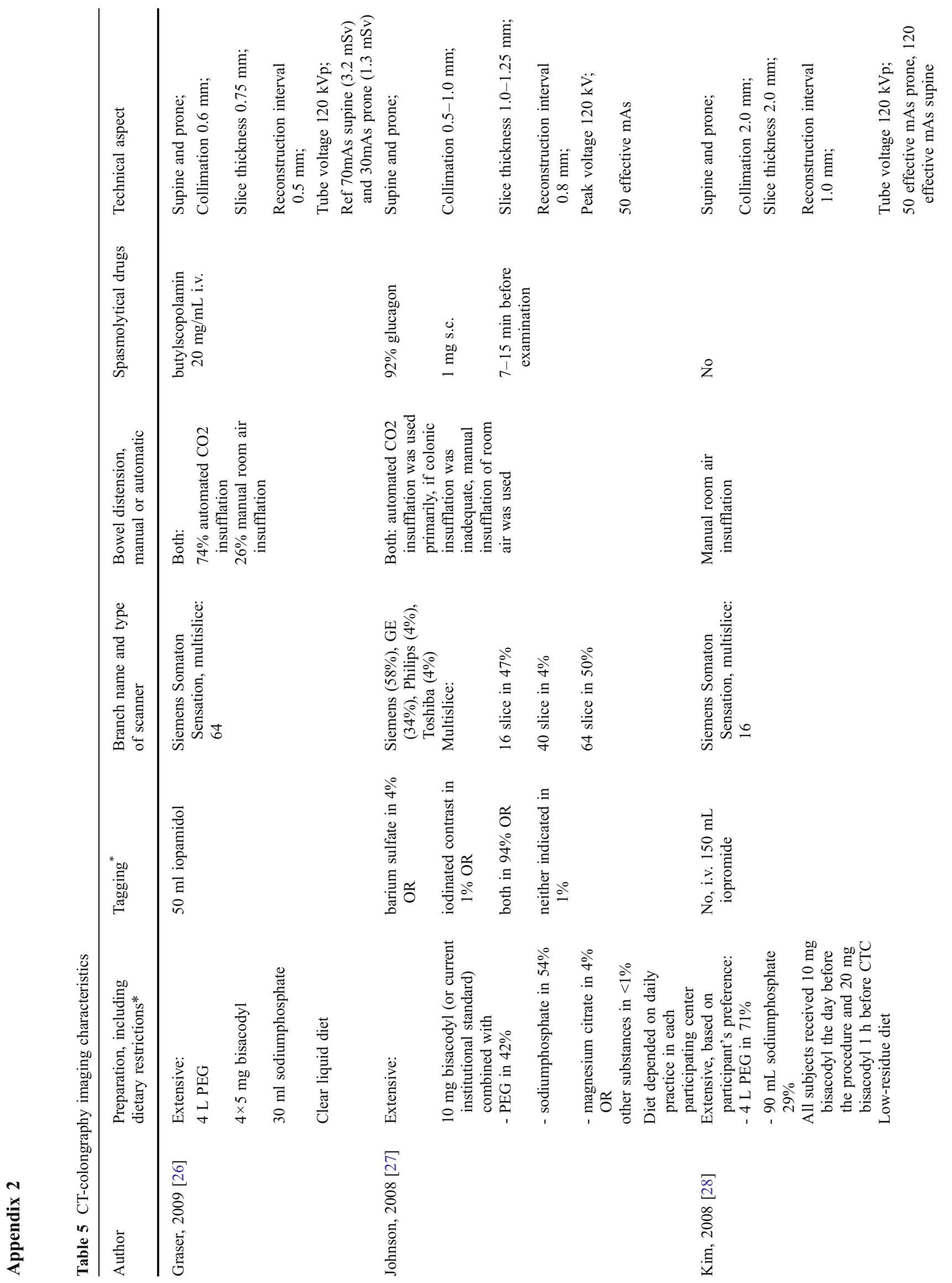



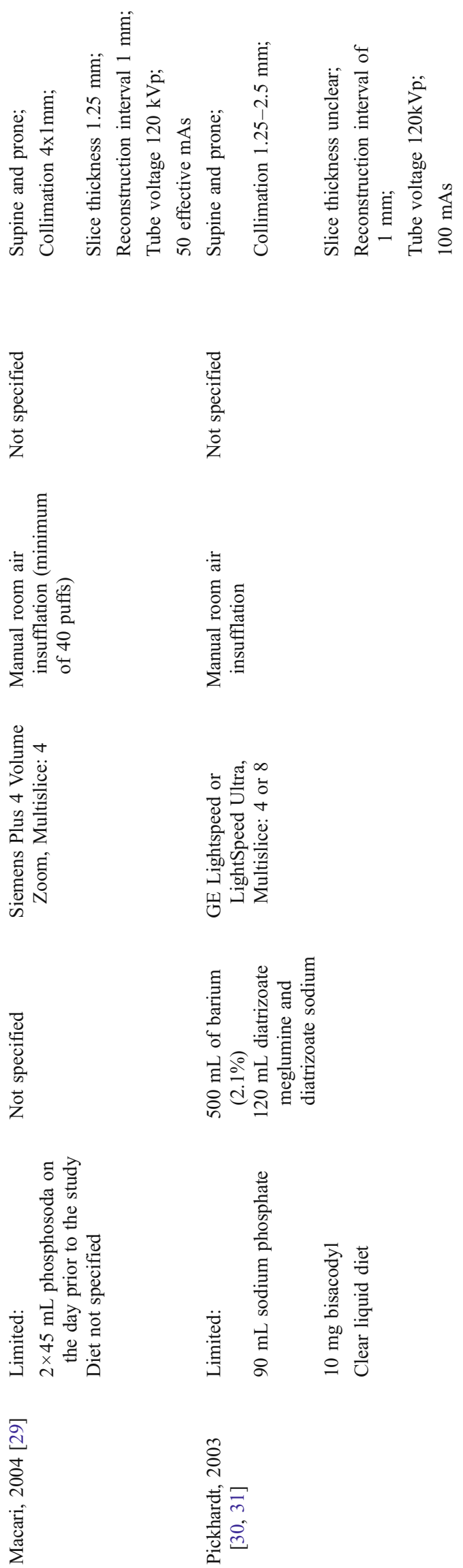


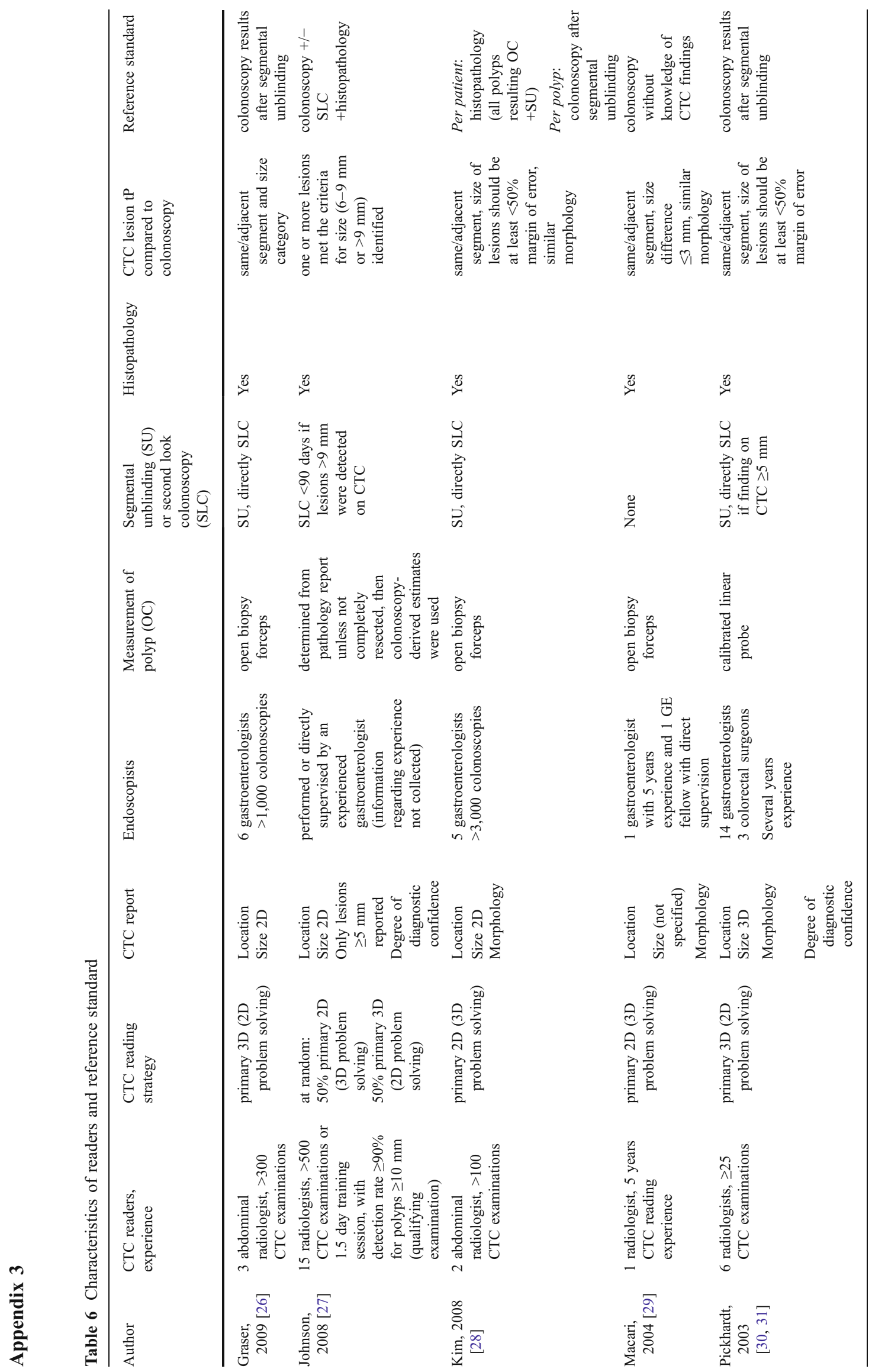




\section{Appendix 4}

a

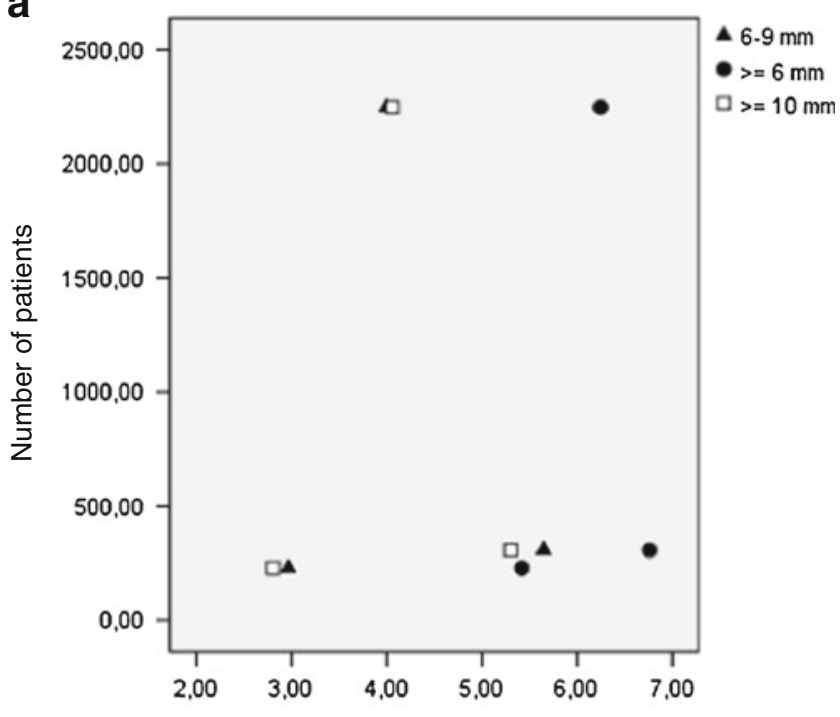

Natural logarithm of the diagnostic odds ratio

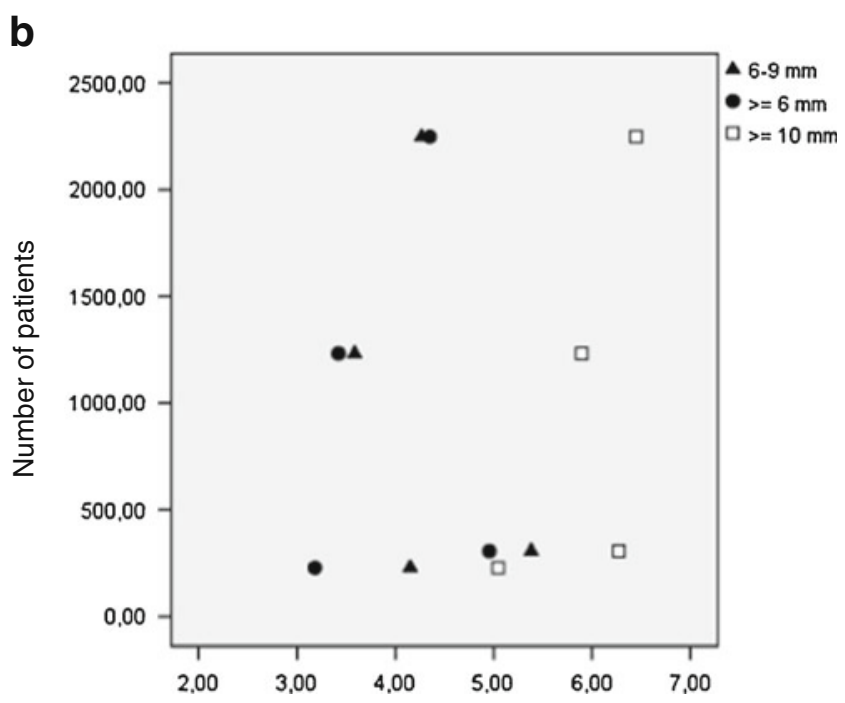

Natural logarithm of the diagnostic odds ratio

Fig. 4 a Funnel plot per patient, all polyps, b Funnel plot per patient, adenomas

\section{Appendix 5}

a
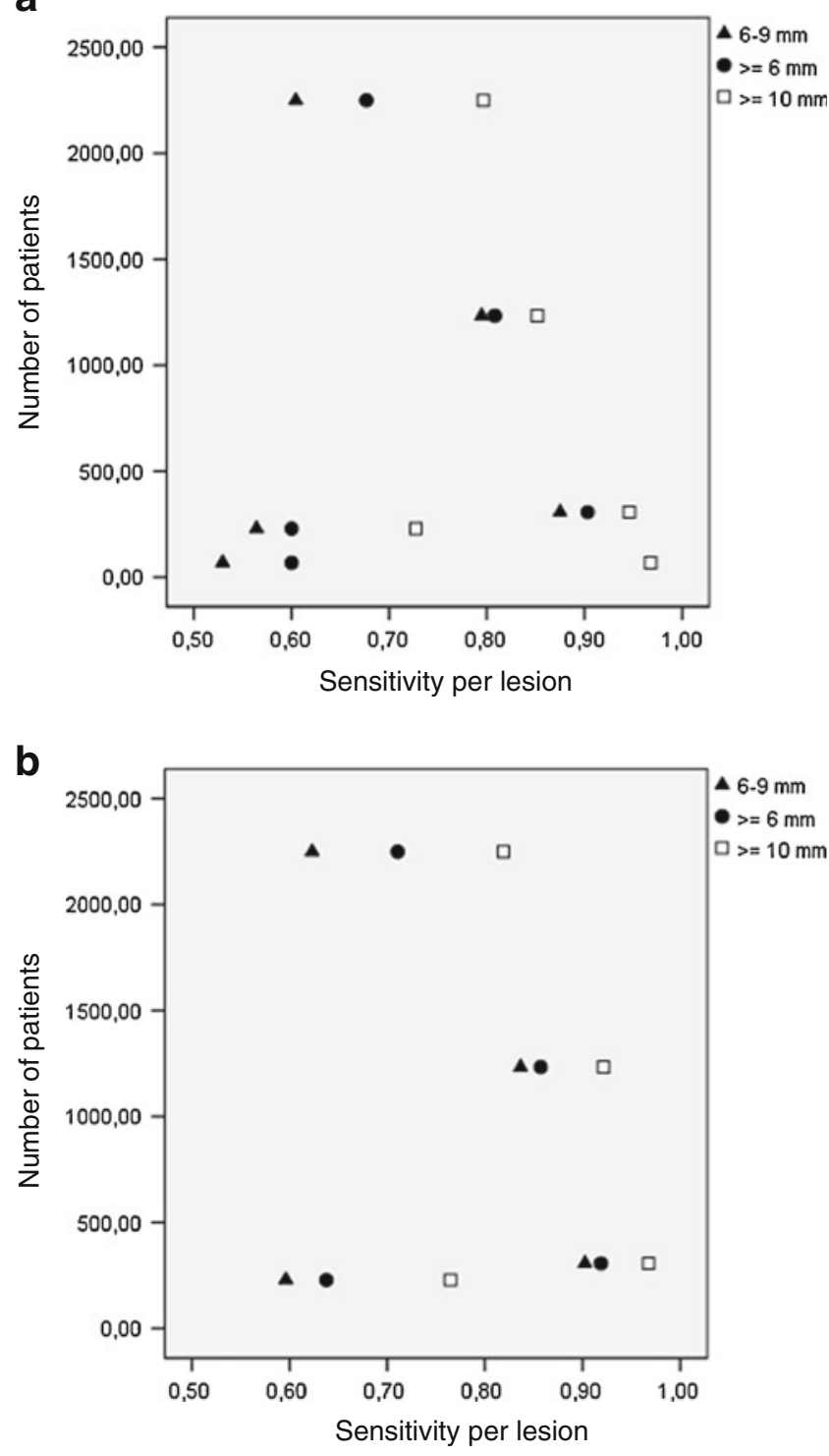

Fig. 5 a Funnel plot per polyp, all polyps, b Funnel plot per polyp, adenomas 


\section{References}

1. McFarland EG, Levin B, Lieberman DA, Pickhardt PH, Johson CD, Glick SN, Brooks D, Smith RA (2008) American Cancer Society; U.S. Multisociety Task Force on Colorectal Cancer; American College of Radiology. Revised colorectal screening guidelines: joint effort of the American Cancer Society, U.S. Multisociety Task Force on Colorectal Cancer, and American College of Radiology. Radiology 248:717-720

2. Levin B, Lieberman DA, McFarland B, Andrews KS, Brooks D, Bond J, Dash C, Giardiello FM, Glick S, Johnson D, Johnson CD, Levin TR, Pickhardt PJ, Rex DK, Smith RA, Thorson A, Winawer SJ (2008) American Cancer Society Colorectal Cancer Advisory Group; US Multi-Society Task Force; American College of Radiology Colon Cancer Committee. Screening and surveillance for the early detection of colorectal cancer and adenomatous polyps, 2008: a joint guideline from the American Cancer Society, the US Multi-Society Task Force on Colorectal Cancer, and the American College of Radiology. Gastroenterology 134:15701595

3. Allen JD, Barlow WE, Duncan RP, Egede LE, Friedman LS, Keating NL, Kim P, Lave JR, Laveist TA, Ness RB, Optican RJ, Steinwachs D, Virnig BA (2010) NIH state-of-the-science conference statement: enhancing use and quality of colorectal cancer screening. NIH Consens State Sci Statements 27

4. Sung JJ, Lau JY, Young GP, Sano Y, Chiu HM, Byeon JS, Yeoh KG, Goh KL, Sollano J, Rerknimitr R, Matsuda T, Wu KC, Ng S, Leung SY, Makharia G, Chong VH, Ho KY, Brooks D, Lieberman DA, Chan FK (2008) Asia Pacific Working Group on Colorectal Cancer. Asia Pacific consensus recommendations for colorectal cancer screening. Gut 57:1166-1176

5. Rex DK, Johnson DA, Anderson JC, Schoenfeld PS, Burke CA, Inadomi JM (2009) American College of Gastroenterology. American College of Gastroenterology guidelines for colorectal cancer screening. Am J Gastroenterol 104:739-750

6. Sosna J, Morrin MM, Kruskal JB, Lavin PT, Rosen MP, Raptopoulos V (2003) CT colonography of colorectal polyps: a metaanalysis. AJR Am J Roentgenol 181:1593-1598

7. Mulhall BP, Veerappan GR, Jackson JL (2005) Meta-analysis: computed tomographic colonography. Ann Intern Med 142:635650

8. Halligan S, Altman DG, Taylor SA, Mallett S, Deeks JJ, Bartram CI, Atkin W (2005) CT colonography in the detection of colorectal polyps and cancer: systematic review, meta-analysis, and proposed minimum data set for study level reporting. Radiology 237:893-904

9. Rosman AS, Korsten MA (2007) Meta-analysis comparing CT colonography, air contrast barium enema, and colonoscopy. Am J Med 120:203-210

10. Chaparro M, Gisbert JP, Del Campo L, Cantero J, Maté J (2009) Accuracy of computed tomographic colonography for the detection of polyps and colorectal tumors: a systematic review and meta-analysis. Digestion 80:1-17

11. Winawer SJ, Fletcher RH, Miller L, Godlee F, Stolar MH, Mulrow CD, Woolf SH, Glick SN, Ganiats TG, Bond JH, Rosen L, Zapka JG, Olsen SJ, Giardiello FM, Sisk JE, Van Antwerp R, BrownDavis C, Marciniak DA, Mayer RJ (1997) Colorectal cancer screening: clinical guidelines and rationale. Gastroenterology 112:594-642

12. Whiting P, Rutjes AW, Reitsma JB, Bossuyt PM, Kleijnen J (2003) The development of QUADAS: a tool for the quality assessment of studies of diagnostic accuracy included in systematic reviews. BMC Med Res Methodol 3:25

13. Winawer SJ, Zauber AG (2002) The advanced adenoma as the primary target of screening. Gastrointest Endosc Clin N Am 12:1-9
14. Iafrate F, Hassan C, Pickhardt PJ, Pichi A, Stagnitti A, Zullo A, Di Giulio E, Laghi A (2010) Portrait of a polyp: the CTC dilemma. Abdom Imaging 35:49-54

15. Bond JH (1993) Polyp guideline: diagnosis, treatment, and surveillance for patients with nonfamilial colorectal polyps. The Practice Parameters Committee of the American College of Gastroenterology Ann Intern Med 119:836-843

16. Lieberman D, Moravec M, Holub J, Michaels L, Eisen G (2008) Polyp size and advanced histology in patients undergoing colonoscopy screening: implications for CT colonography. Gastroenterology 135:1100-1105

17. Higgins JP, Thompson SG, Deeks JJ, Altman DG (2003) Measuring inconsistency in meta-analyses. BMJ 327:557-560

18. Reitsma JB, Glas AS, Rutjes AW, Scholten RJ, Bossuyt PM, Zwinderman AH (2005) Bivariate analysis of sensitivity and specificity produces informative summary measures in diagnostic reviews. J Clin Epidemiol 58:982-990

19. Arnesen RB, von Benzon E, Adamsen S, Svendsen LB, Raaschou HO, Hansen OH (2007) Diagnostic performance of computed tomography colonography and colonoscopy: a prospective and validated analysis of 231 paired examinations. Acta Radiol 48:831-837

20. Fidler JL, Johnson CD, MacCarty RL, Welch TJ, Hara AK, Harmsen WS (2002) Detection of flat lesions in the colon with CT colonography. Abdom Imaging 27:292-300

21. Wessling J, Domagk D, Lugering N, Schierhorn S, Heindel W, Domschke W, Fischbach R (2005) Virtual colonography: identification and differentiation of colorectal lesions using multi-detector computed tomography. Scand J Gastroenterol 40:468-476

22. Rex DK, Vining D, Kopecky KK (1999) An initial experience with screening for colon polyps using spiral CT with and without CT colography (virtual colonoscopy). Gastrointest Endosc 50:309-313

23. Pineau BC, Paskett E, Chen GJ, Espeland MA, Philips K, Han JP, Mikulaninec C, Vining DJ (2003) Virtual colonoscopy using oral contrast compared with colonoscopy for the detection of patients with colorectal polyps. Gastroenterology 125:304-310

24. Iannaccone R, Laghi A, Catalano C, Brink JA, Mangiapane F, Trenna S, Piacentini F, Passariello R (2003) Detection of colorectal lesions: lower-dose multi-detector row helical CT colonography compared with conventional colonoscopy. Radiology 229:775-781

25. An S, Lee KH, Kim YK, Park SH, Kim HY, Kim SH, Kim N (2008) Screening CT colonography in an asymptomatic averagerisk Asian population: a 2-year experience in a single institution. Am J Roentgenol 191:W100-W106

26. Graser A, Stieber P, Nagel D, Schäfer C, Horst D, Becker CR, Nikolaou K, Lottes A, Geisbüsch S, Kramer H, Wagner AC, Diepolder H, Schirra J, Roth HJ, Seidel D, Göke B, Reiser MF, Kolligs FT (2009) Comparison of CT colonography, colonoscopy, sigmoidoscopy and faecal occult blood tests for the detection of advanced adenoma in an average risk population. Gut 58:241-248

27. Johnson CD, Chen MH, Toledano AY, Heiken JP, Dachman A, Kuo MD, Menias CO, Siewert B, Cheema JI, Obregon RG, Fidler JL, Zimmerman P, Horton KM, Coakley K, Iyer RB, Hara AK, Halvorsen RA Jr, Casola G, Yee J, Herman BA, Burgart LJ, Limburg PJ (2008) Accuracy of CT colonography for detection of large adenomas and cancers. N Engl J Med 359:1207-1217

28. Kim YS, Kim N, Kim SH, Park MJ, Lim SH, Yim JY, Cho KR, Kim SS, Kim DH, Eun HW, Cho KS, Kim JH, Choi BI, Jung HC, Song IS, Shin CS, Cho SH, Oh BH (2008) The efficacy of intravenous contrast-enhanced 16-raw multidetector CT colonography for detecting patients with colorectal polyps in an asymptomatic population in Korea. J Clin Gastroenterol 42:791798 
29. Macari M, Bini EJ, Jacobs SL, Naik S, Lui YW, Milano A, Rajapaksa R, Megibow AJ, Babb J (2004) Colorectal polyps and cancers in asymptomatic average-risk patients: evaluation with CT colonography. Radiology 230:629-636

30. Pickhardt PJ, Choi JR, Hwang I, Butler JA, Puckett ML, Hildebrandt HA, Wong RK, Nugent PA, Mysliwiec PA, Schindler WR (2003) Computed tomographic virtual colonoscopy to screen for colorectal neoplasia in asymptomatic adults. N Engl J Med 349:2191-2200

31. Pickhardt PJ, Choi JR, Hwang I, Schindler WR (2004) Nonadenomatous polyps at CT colonography: prevalence, size distribution, and detection rates. Radiology 232:784-790

32. Pickhardt PJ, Lee AD, Taylor AJ, Michel SJ, Winter TC, Shadid A, Meiners RJ, Chase PJ, Hinshaw JL, Williams JG, Prout TM,
Husain SH, Kim DH (2007) Primary 2D versus primary 3D polyp detection at screening CT colonography. AJR Am J Roentgenol 189:1451-1456

33. De Vries AH, Liedenbaum MH, Bipat S, Truyen R, Serlie IW, Cohen RH, van Elderen SG, Heutinck A, Kesselring O, de Monyé W, te Strake L, Wiersma T, Stoker J (2009) Primary uncleansed $2 \mathrm{D}$ versus primary electronically cleansed $3 \mathrm{D}$ in limited bowel preparation CT-colonography. Is there a difference for novices and experienced readers? Eur Radiol 19:1939-1950

34. Howson, Colin, Peter Urbach (1993) Scientific reasoning: The Bayesian approach. Open Court

35. Van Rijn JC, Reitsma JB, Stoker J, Bossuyt PM, van Deventer SJ, Dekker E (2006) Polyp miss rate determined by tandem colonoscopy: a systematic review. Am J Gastroenterol 101:343-350 